\title{
Investigation on the Performance of TiN Coatings by Reactive Plasma Spraying Crystallization
}

\author{
Wenyan Qi a, Pengxian Song ${ }^{b}$, Zhiyong Gan ${ }^{c}$, Fang Ye ${ }^{d}$, Siwei Fu ${ }^{e}$, Tian $\mathrm{Li}^{\dagger}$, \\ Xunda Zhang ${ }^{g}$
}

Tianjin Electric Power Corporation Electric Power Research Institute, Tianjin 300384, China.

adqiwenyan@126.com, bsongpengxian0821@163.com, 'chiyong.gan@tj.sgcc.com.cn,

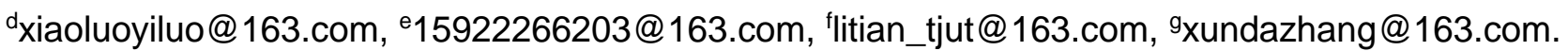

Keywords: Tin Coatings, Reactive Plasma Spraying, The Laws Of Crystallization.

\begin{abstract}
TiN coatings were prepared by means of reactive plasma spraying (RPS) titanium powders, and characterized by SEM, XRD and other methods in the paper. In order to optimize spraying process parameters and get a satisfactory spraying effect, the microstructure, the hardness, the organizations and phases of TiN coatings under different spraying power were studied; also the grain size and the laws of crystallization were analyzed. The results showed that TiN coatings were consisted of TiN phase and a few of $\mathrm{TiO}^{0.325}$ and $\mathrm{Ti}_{2} \mathrm{O}_{3}$. A large number of small equiaxed crystals, columnar crystals and part of branches crystals formed the microstructure of the TiN coatings. The cross-sectional hardness of the TiN coating was higher than the surface hardness under the same compression load. Moreover, the TiN coatings which were more close to the substrate material had larger undercooling when crystalling, and the grain size was smaller.
\end{abstract}

\section{Introduction}

Plasma spraying is a widely used in material surface strengthening and surface modification technology, which can make the substrate surface with the performance of wear, corrosion resistance, high temperature oxidation resistance and heat insulation. However, it is difficult to prepare a coating with ceramic inherent properties, because some particles could not be completely melted in the process of coating formation, and powder was mixed in the coating, so the excellent wear resistance and corrosion resistance of ceramic material were restricted [1-4].

The powder used in reactive plasma spraying is generally a highly exothermic reaction system. The powder reacts with the reaction gas during flight and the reaction product particles are deposited onto the substrate to form the coating which is typical lamellar structure [5]. The superposition of synthesis reaction heat and plasma arc is beneficial to the melting of hard phase with high melting point, which overcomes the difficulties of the uneven distribution of hard plasma spraying, melting incomplete, coarse microstructure and so on [6]. A good combination of the hard phase and the matrix is helping to improve the wear resistance and corrosion resistance of the composite coating [7].

At present, the application of reactive plasma spraying technology has been relatively matured, a variety of coatings have been successfully prepared, such as $\mathrm{Fe}-\mathrm{TiB}_{2}$ coating and $\mathrm{TiN}$ coating. TiN coating with a thickness of $150 \mu \mathrm{m}$ was prepared by Akira Kobayashi et al. using gas tunnel plasma spray gun reactive spraying [8]. TiN coating was prepared in a nitrogen-filled spray booth using reactive plasma spraying by T. Bacci et al. [9]. E. Galvanetoo et al. studied the wear and corrosion properties of Ti-TiN coatings prepared by reactive plasma spraying [10].

But the above coatings are rougher, and a number of holes existed in the coatings, which reduce the coatings' performance greatly. The high hardness and excellent wear resistance of TiN coating cannot be shown totally because of the remnant Ti powder leading to the application of TiN coating has been limited. Although TiN coating has been prepared by reactive plasma spraying and some investigation was carried out, few attentions have been paid to the laws of crystallization in the process of formation of the coating. 


\section{Experimental}

20\# carbon steel was used as substrate material. Rectangular specimens (10 mm $\times 10 \mathrm{~mm} \times 12 \mathrm{~mm})$ for coating deposition were fabricated and ground with $\mathrm{SiC}$ papers, followed by ultrasonically cleaning in acetone for $30 \mathrm{~min}$. After that, $\mathrm{NiAl}$ adhesive layer with a thickness of $100 \mu \mathrm{m}$ were deposited on the specimens. Then the TiN coating of about $300 \mu \mathrm{m}$ thickness was produced by spraying titanium powder on $\mathrm{NiAl}$ adhesive layer. The ingredient of $\mathrm{Al} / \mathrm{Ni}$ powder and $\mathrm{Ti}$ powder was listed in Table 1 and Table 2 respectively.

Table 1. The ingredients of $\mathrm{Ni} / \mathrm{Al}$ powder in the experiment

\begin{tabular}{|c|c|c|c|}
\hline Elements & $\mathrm{Ni}$ & $\mathrm{Al}$ & Others \\
\hline wt.\% & 90 & $\mathrm{Bal}$ & $<1.0$ \\
\hline
\end{tabular}

Table 2. The ingredients of Ti powder in the experiment

\begin{tabular}{|c|c|c|c|c|c|c|c|c|}
\hline Elements & $\mathrm{Ti}$ & $\mathrm{Fe}$ & $\mathrm{Si}$ & $\mathrm{Cl}$ & $\mathrm{C}$ & $\mathrm{N}$ & $\mathrm{O}$ & $\mathrm{H}$ \\
\hline wt.\% & $>99.4$ & $<0.06$ & $<0.02$ & $<0.01$ & $<0.02$ & $<0.04$ & $<0.4$ & $<0.02$ \\
\hline
\end{tabular}

A plasma spraying system (GP-80) equipped with power supply cabinet, plasma spray gun, gas supply system, circulating cooling system, powder feeder and working table was used for preparing the TiN coating. The process parameters of $\mathrm{TiN}$ coating prepared by reactive plasma spraying were listed in Table 3.

Table 3. Reactive plasma spraying parameters of TiN coatings

\begin{tabular}{|c|c|c|c|c|c|c|}
\hline \multirow{2}{*}{$\begin{array}{l}\text { spraying } \\
\text { power/kw }\end{array}$} & \multicolumn{2}{|c|}{ gas-flow rate $/ \mathrm{L} \cdot \mathrm{min}^{-1}$} & \multirow{2}{*}{$\begin{array}{c}\text { input } \\
\text { voltage/V }\end{array}$} & \multirow{2}{*}{$\begin{array}{c}\text { input voltage } \\
\text { /A }\end{array}$} & \multirow{2}{*}{$\begin{array}{c}\text { powder } \\
\text { feeding } \\
\text { rate } / \mathrm{L} \cdot \mathrm{min}^{-1}\end{array}$} & \multirow{2}{*}{$\begin{array}{c}\text { spraying } \\
\text { distance/ } \\
\mathrm{mm}\end{array}$} \\
\hline & $\mathrm{N}_{2}$ & $\mathrm{Ar}$ & & & & \\
\hline 28 & 50 & 50 & 80 & 350 & 3 & 100 \\
\hline 32 & 50 & 50 & 80 & 400 & 3 & 100 \\
\hline 36 & 50 & 50 & 80 & 450 & 3 & 100 \\
\hline 40 & 50 & 50 & 80 & 500 & 3 & 100 \\
\hline
\end{tabular}

The surface and cross-section of TiN coatings were grinded, polished, cleaned with alcohol and dried. In order to observe the microstructure and grain morphology of TiN coating, it is necessary to corrode the surface of the coatings after grinding and polishing. The corrosion agent used is $10 \% \mathrm{HF}$ and $50 \%$ nitric acid alcohol solution in proportion of $4: 1$.

The phases of the TiN coating were analyzed by X-ray diffraction, and the grain size of the coating was calculated by Scherrer formula. The coating close to the substrate surface was analyzed, in order to further study the crystallization rules of TiN coating. The TiN coating was sprayed again after it formed for 48 hours, and a part of the TiN coating was peeled off because of the thermal stress, and the coating tightly bonded to the substrate was exposed. The second sprayed sample was polished, etched and then observed by SEM.

\section{Results and discussion}

\subsection{XRD analysis of the TiN coatings.}

The TiN coatings were prepared with different power parameters according to the test parameters in Table 3. The phases of the TiN coating were analyzed by X-ray diffraction after the oxide layer on the surface was polished off by $\mathrm{SiC}$ papers. The XRD patterns of the TiN coatings are presented in Fig. 1.

The XRD results show that the TiN coatings prepared by different spraying power are consisted of TiN phase and a few of $\mathrm{TiO}_{0.325}$ and $\mathrm{Ti}_{2} \mathrm{O}_{3}$, but the percentage of each phase is slightly different. TiN is the main phase, indicating that the Ti powder combust in the plasma flam and form TiN droplets which impact to the substrate surface under the accelerated action of the flame and then spread to cooling, and form lamellar TiN coating finally. The TiN coating contains a small amount of $\mathrm{TiO}_{0.325}$ when the spraying power is $28 \mathrm{kw}$, which may be caused by the oxidation of Ti powder during the 
spraying process, or the TiN droplets may be oxidized during the flight. The oxidation degree of Ti becomes larger with the increasing of the spraying power, because $\mathrm{TiO}_{0.325}$ is further oxidized when the substrate temperature is extremely high and $\mathrm{Ti}_{2} \mathrm{O}_{3}$ phase exists in the coating when the spraying power is $40 \mathrm{kw}$. It is noted that although the $\mathrm{TiO}_{2}$ phase is not found in the results, the TiN coating will be eventually oxidized to $\mathrm{TiO}_{2}$ if the coating is exposed in air for long time.

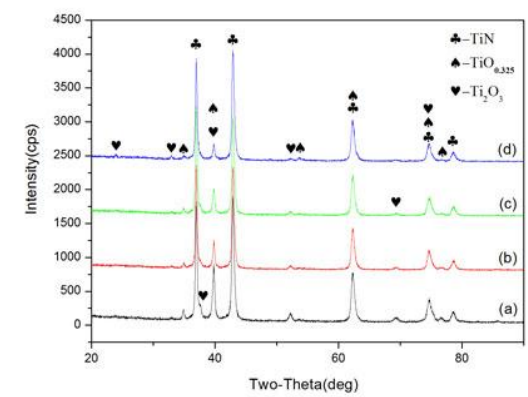

Fig. 1 The XRD pattern of TiN coatings of different spraying power

(a) $28 \mathrm{kw}$ (b) $32 \mathrm{kw}$ (c) $36 \mathrm{kw}$ (d) $40 \mathrm{kw}$

\subsection{The morphology of the TiN coatings.}

The surface morphologies of the TiN coating prepared under the spraying power of $28 \mathrm{kw}$ are presented in Fig.2. It can be seen that TiN coating surface was in the form of droplets, illustrating that the Ti powder is fully melted in the plasma flame to form droplets. The droplets are accelerated in the plasma flame and eventually impinge on the substrate at a high velocity, spread out and solidify layered coating. Some micro-cracks can be observed on the surface of TiN coating from Fig. 2b, which are caused by the residual thermal stress during the rapid cooling, solidification and contraction of the droplets on the substrate [11].

From the cross-sectional morphologies of the TiN coating prepared at $28 \mathrm{kw}$ as shown in Fig. 3 typical lamellar structure can be seen and the thickness of TiN lamellar structure is uniform. In addition, some holes can also be found in the TiN coating.
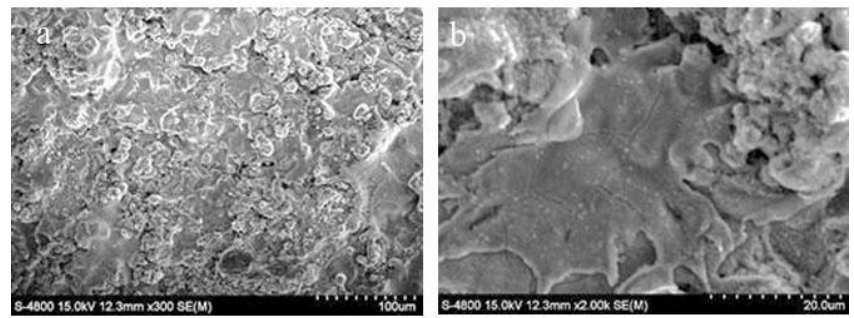

Fig.2 Surface morphologies of the TiN coatings (a) $300 \times$, (b) $2000 \times$
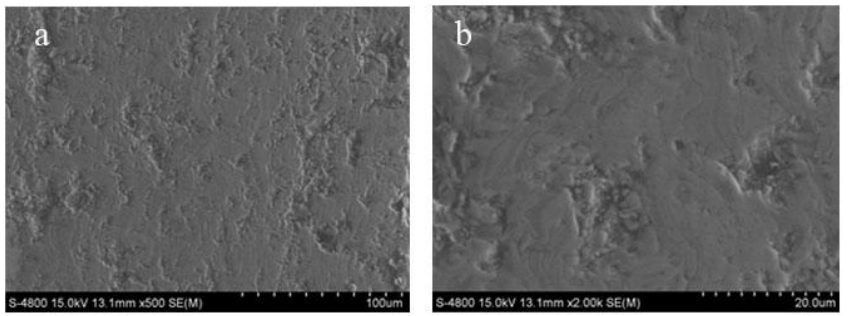

Fig. 3 Cross-sectional morphologies of the TiN coatings (a) 500×, (b) 2000x

The grain and grain boundary morphology of the TiN coating prepared at $28 \mathrm{kw}$ were observed by SEM, after the TiN coating was etched with high concentration of hydrofluoric acid. Fig. 4 shows the different organizations of nanocrystalline TiN coatings. It can be seen that the nanocrystalline grains existed in the TiN coatings and the distribution of nanocrystalline were uniform. There are a lot of fine equiaxed grains, columnar crystals and a certain amount of dendrites in the TiN coatings.

Fig.4a shows the size of the equiaxed crystal is $60 \sim 100 \mathrm{~nm}$. The substrate temperature was much lower than TiN droplets temperature when TiN droplets encountered the matrix during flight, the thin layer close to the substrate had a strong undercooling, and the fine convex on substrate surface can be 
used as the nucleation of the substrate in the crystal. A large number of nuclei formed in these convex, and quickly grew up until contacted with each other to form a small equiaxed crystal.

A certain number of columnar crystals exist in the TiN coatings as shown in Fig. 4b. The diameter of the columnar crystal is about $70 \mathrm{~nm}$, and the columnar crystal is similar to the lath martensitic structure which is composed of a series of parallel rod-like basic unit. The growth direction of the columnar crystals is nearly parallel with the coating surface. The formation of columnar crystals is related to the direction of heat dissipation during crystal growth, and the grains grow into columnar crystals in the direction of rapid heat dissipation. For the reactive plasma sprayed TiN coating, the TiN droplets cool down rapidly to form a large number of nuclei as the TiN droplets deposited on the substrate surface. As the crystal grains are continuously formed, the temperature of the substrate increases and the droplets cool rapidly arriving at the substrate and latent heat is released at the time of crystallization, so that the undercooling degree becomes low and nucleation becomes difficult [12]. In this case, the crystal nuclei form along the rapid heat radiation direction of growth speed, the substrate surface are convex after sand blasting, heat dissipation direction is not the same of different location, which results in the growth direction of the crystal is different.

From Fig. 4c, it can be seen some dendrites existed in the coating. Moreover, the primary crystal axis of the dendrites is coarse, and the secondary crystal axis which is perpendicular to the primary crystal axis is significantly finer than the primary axis. The process of plasma spraying to form the coating is a process in which molten droplets form nuclei at very large cooling rates (up to $10^{6} \sim 10^{8} \mathrm{~K}$ $/ \mathrm{s}[13,14])$ and undercooling. Further study should be carried out to prove the formation of dendrites may be related to this.
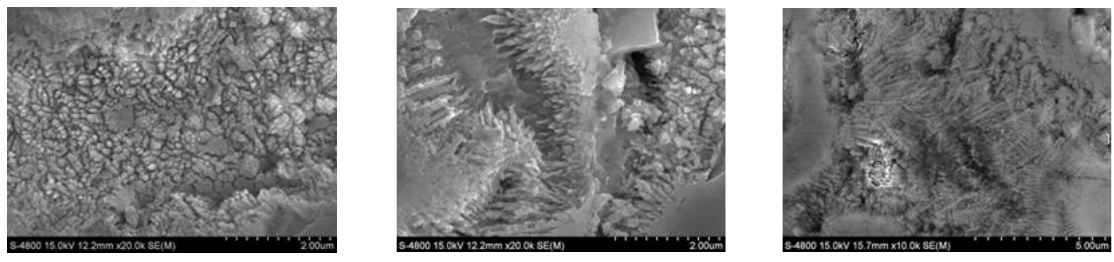

(a) equiaxed crystal area (b)columnar crystal area (c) branches crystal area

Fig.4 Different organizations of nanocrystalline TiN coatings

The grain morphology on the front and back side of the TiN coating is shown in Fig. 5. The results show that the grains on the backside of the TiN coating are finer under the same spraying parameters, because the substrate temperature is the lowest when the first drop of TiN droplet contact with the substrate, and the nucleation rate is the highest.
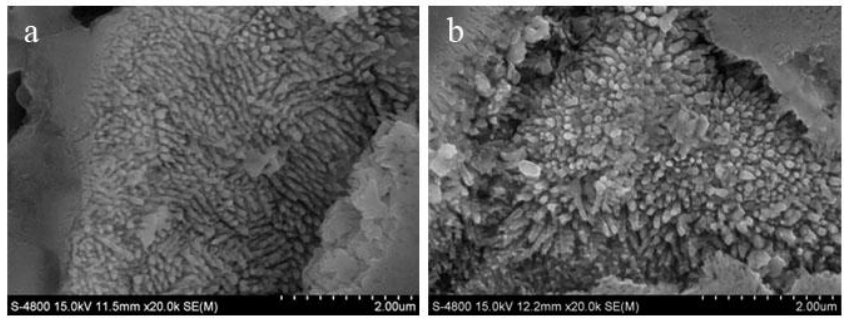

Fig.5 The grain morphology on the TiN coating (a) the bottom (b) the surface

It can also be seen that the directionality of the growth of the bottom grain is poor and the growth direction of the columnar crystals close to the surface layer is at an angle to the coating surface from Fig. 5. This is because the amount of the TiN droplets on the substrate is very small at the beginning of crystallization, and the droplets can dissipate in multiple directions during the solidification process, resulting in a more chaotic grain growth direction. The TiN coating temperature is getting higher and higher as TiN droplets continue to condense on coating surface, and the heat dissipation is the fastest in the direction perpendicular to the coating surface, which lead to the columnar crystals formed later grew up in the direction perpendicular to the coating surface. 


\subsection{The surface and cross-sectional hardness of TiN coatings.}

Fig. 6 shows the surface and cross-sectional hardness of TiN coatings prepared by $40 \mathrm{kw}$ measured with a pressing load of $0.98 \mathrm{~N}, 1.96 \mathrm{~N}, 2.94 \mathrm{~N}, 4.9 \mathrm{~N}$ and $9.8 \mathrm{~N}$. According to the results, the cross-section hardness of the TiN coating is higher obvious than the surface hardness under the same compression load. This can be explained that the multiple layers of the coating are subjected to pressure coordinated deformation when the cross-section of the coating is under compression because of the lamellar structure of TiN coating, which makes the deformation more difficult with respect to the surface. In addition, the cross-sectional hardness and the surface hardness decreases with increasing of pressing load, namely the hardness measured by indentation techniques generally shows a decrease with increasing test load.

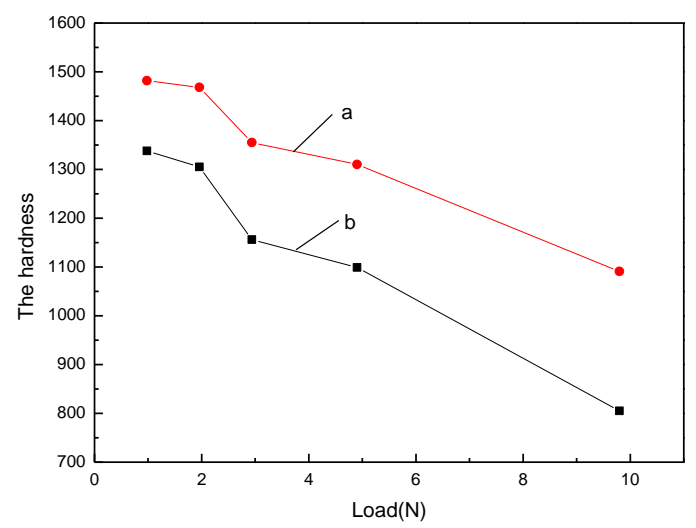

Fig.6 Comparison of surface and cross-sectional hardness of TiN coatings prepared by 40kw under different load (a) cross-sectional hardness (b) surface hardness

\subsection{Effect of spraying power on grain size of TiN coatings.}

The grain size of the TiN coatings prepared at different spraying powers calculated by Scherrer formula [15] is shown in Table 4. It can be inferred that the calculated grain size of the TiN coating sprayed at $28 \mathrm{kw}$ is consistent with its microstructure observed by SEM in Fig. 4a, indicating that it is feasible to evaluate the grain size of TiN coating by Scherrer formula. At the same spraying distance, the grain size of TiN coating increases with the increasing of the spraying power.

It is worth noting that the plasma flame flow enthalpy increases with the increasing of spraying power when the spray distance remains unchanged, and the temperature of the substrate increases with the increasing of the plasma flame flow enthalpy. It was found that the substrate could easily be reddish by the plasma flame when the spraying power exceeded $32 \mathrm{kw}$ during the spraying process. The increasing of substrate temperature means that the crystallization temperature of the TiN droplets will increase, namely the supercooling degree of TiN crystallization will decrease, which leads to decrease of the nucleation rate and increase of the grain growth rate in the crystallization process.

Table 4. The grain size of TiN coatings under different spraying power parameter

\begin{tabular}{|c|c|c|c|c|}
\hline \multirow{2}{*}{ numbers } & \multirow{2}{*}{ spraying power/kw } & \multicolumn{2}{|c|}{$\mathrm{D}_{h k l} / \mathrm{nm}$} & average grain size / \\
\cline { 2 - 4 } & & $(111)$ & $(200)$ & $\mathrm{nm}$ \\
\hline 1 & 28 & 80.06 & 68.83 & 74.45 \\
2 & 32 & 93.09 & 67.03 & 80.06 \\
3 & 36 & 93.85 & 67.37 & 80.61 \\
4 & 40 & 96.21 & 74.16 & 85.19 \\
\hline
\end{tabular}

\section{Summary}

The TiN coatings were produced by reactive plasma spraying in different spraying process parameters. The microstructure, the hardness, the organizations and phases of TiN coatings under different spraying power were investigated; also the grain size and the laws of crystallization were analyzed. Some conclusions can be drawn as follows: 
(1) XRD results show that the TiN coatings prepared by different spraying power are consisted of TiN phase and a few of $\mathrm{TiO}_{0.325}$ and $\mathrm{Ti}_{2} \mathrm{O}_{3}$. The TiN coating has a lamellar structure, and the bonding between each layer is close, but a small amount of pores and micro-crack exists in TiN coatings.

(2) The TiN coating is consisted of fine columnar crystals, equiaxed grains and some dendrites which also include the secondary axis and the third axis. Under the same spraying parameters, the grains on the bottom of the coating are finer comparing with the surface of the coating.

(3) The cross-sectional hardness of the TiN coating is higher obvious than the surface hardness under the same compression load because of the lamellar structure of TiN coating.

(4) The average grain size of TiN coating is increasing as spraying power increased.

\section{References}

[1]. Baikun Wang.Study on the mechanism of toughening of structural ceramics. China Science and Technology Information, 2007,19: 264-273.

[2]. Jining He, Yanzheng Liu, Dianran Yan, et al. Corrosion Behavior of Ni/Al-13wt $\% \mathrm{TiO}_{2} / \mathrm{Al}_{2} \mathrm{O}_{3}$ Graded Composite Ceramic Coatings on Metal Substrate.Acta Ceramics Sinica, Vol. 1 (2002) No. 23, p. 29-29.

[3]. Xuecheng LU, Dianran YAN, Ying REN.Study on the Interface of Plasma Sprayed Ceramics . Acta Ceramics Sinica, Vol. 1 (2009) No. 30, p. 117-123.

[4]. BinShi Xu.Chinese Surface Engineering Development. China Mechanical Engineering Society 60th Anniversary of Advanced Manufacturing Technology Conference Proceedings, 1996.

[5]. Zhengyong Cheng, Zhengcui Cheng, Jiangsu Li, et al.Thermal Spraying Technology and Ceramic Coating. Heat Treatment, Vol. 18 (2003) No. 1, p. 5-8.

[6]. Xin Ji, Yiming Mi, Xiying Zhou. Progress in the preparation and properties of TiN films and their applications. Hot Working Technology, Vol. 38 (2009) No. 4, p. 81-84.

[7]. Shijun Deng. High-performance ceramic coating. Beijing Chemical Industry Press, 2004, p.48-63.

[8]. Akira kobayashi. Formation of TiN coatings by gas tunnel type plasma reactive spraying. Surface and Coatings Technology, Vol. 132 (2000) No. 1, p. 152-157.

[9]. Bacci T, Bertamini L, Ferrari F, et al. Reactive plasma spraying of titanium in nitrogen containing plasma gas. Materials Science and Engineering, Vol. 283 (2000), p.189-195.

[10]. Galvanetoo E, Galliano F, Borgioli F, et al. XRD and XPS study on reactive plasma sprayed titanium-titanium nitride coatings. Thin Solid Films, Vol. 384 (2001), p.223-229.

[11]. Qicheng Liu, Peiying Liu, Ye Tao. CVD and PVD TiN thin films. Materials Engineering, 2000, Vol. 12 (2000), p.22-25.

[12]. Bo Liang, Chuanxian Ding. Phase composition of nanostructured zirconia coatings deposited by air plasma spraying. Surface and Coatings Technology, Vol. 191 (2005), p. 267-273.

[13]. Zeng Y, Lee S, Gao L, et al. Atmospheric plasma sprayed coatings of nanostructured zirconia. Journal of the European Ceramic Society, Vol. 22 (2002), p.347-351.

[14]. Thierry Grosdidier, Gang Ji, Frederic Bernard, et al. Synthesis of bulk FeAl nanostructured materials by HVOF spray forming and Spark Plasma Sintering. Intermetallics, Vol. 14 (2006), p.1208-1213.

[15]. Fuzhi Wang. Materials of modern analytical methods. Beijing Institute of Technology, 2010, p.93. 